\title{
Amyloidosis and systemic lupus erythematosus
}

\author{
MARTIN G. RIDLEY, ${ }^{1}$ PETER J. MADDISON ${ }^{2}$ AND COLIN R. TRIBE \\ From the ${ }^{1}$ Royal United Hospital, Bath, the ${ }^{2}$ Royal National Hospital for Rheumatic Diseases, Bath, and \\ ${ }^{3}$ Southmead Hospital, Bristol
}

SUMMARY A patient with systemic lupus erythematosus who developed reactive amyloidosis associated with high levels of serum amyloid-A protein (SAA) is reported. The possible relevance of elevated SAA levels in the aetiology of amyloidosis is discussed.

Amyloidosis may complicate many rheumatological conditions and other diseases associated with chronic inflammation. The factors which render certain individuals with similar diseases susceptible to amyloid production are not clear. Recently it has been suggested that levels of the acute phase reactant serum amyloid-A protein (SAA) appear to correlate with amyloid development. ${ }^{1}$ We describe a patient with systemic lupus erythematosus (SLE), a disease rarely associated with amyloidosis, who developed severe renal amyloidosis and was found to have a very high level of SAA.

\section{Case report}

A 56-year-old Caucasian male presented in August 1971 with malaise and a photosensitive, maculopapular rash, predominantly on the trunk, arms, and legs. Investigations showed an erythrocyte sedimentation rate (ESR) of $118 \mathrm{~mm}$ in the first hour, leucopenia $\left(1.5 \times 10^{9} / 1\right)$, and a polyclonal elevation of IgG. Antinuclear antibodies (ANA) were not detected. A skin biopsy, however, was consistent with SLE, with epidermal atrophy, liquefaction necrosis of the basal layer, and patchy lymphocytic infiltration. The rash was controlled with prednisolone $5 \mathrm{mg}$ to $10 \mathrm{mg}$ daily, but the leucopenia and the raised IgG persisted. In 1978 his creatinine clearance was $87 \mathrm{ml} / \mathrm{min}$ with no evidence of proteinuria.

In May 1981 he was admitted with worsening of the rash, together with proteinuria. On examination there was a widespread maculopapular rash with

Accepted for publication 9 January 1984.

Correspondence to Dr P. J. Maddison, Royal National Hospital for Rheumatic Diseases, Upper Borough Walls, Bath BA1 1RL. scaling consistent with papulosquamous cutaneous lupus erythematosus. ${ }^{2}$ There was also a chronic ulcer $(2 \times 2 \mathrm{~cm})$ over the left ankle, and the foot pulses were absent. This had been present for one year but was clean on admission, without evidence of infection, and there was no clinical or radiological evidence of underlying osteomyelitis.

Laboratory findings included a white cell count of $1.9 \times 10^{9} / \mathrm{l}$ and a 24 hour protein excretion of $4.9 \mathrm{~g}$. Urinary microscopy showed only tubular casts. The serum creatinine was $101 \mu \mathrm{mol} / \mathrm{l}$ and the creatinine clearance $73 \mathrm{ml} / \mathrm{min}$. The plasma globulin was $47 \mathrm{~g} / \mathrm{l}$, with no paraprotein on electrophoresis. The ANA test was negative by immunofluorescence, but precipitating antibodies to Ro(SSA) ${ }^{3}$ were detected by immunodiffusion.

C-reactive protein (CRP) and SAA levels were measured by radial immunodiffusion in the laboratory of Dr J. T. Whicher. The CRP assay used antiserum from Seward Laboratories, London, and the lower limit of sensitivity is $0.005 \mathrm{~g} / \mathrm{l}$ (normal range $<0.005-0.011 \mathrm{~g} / \mathrm{l})$. The SAA assay used antiserum from Atlantic Antibodies, Westbrook, Maine, and the lower limit of sensitivity is $0.002 \mathrm{~g} / \mathrm{l}$ (normal range $<0.002-0.030 \mathrm{~g} / \mathrm{l}$ ). The results of the analysis for acute phase proteins showed a greatly elevated level of serum amyloid-A protein at 0.979 $\mathrm{g} / \mathrm{l}$ and a moderately raised $\mathrm{C}$-reactive protein at $0.05 \mathrm{~g} / \mathrm{l}$. This was the only estimation made of acute phase proteins.

A repeat skin biopsy showed a patchy lymphocytic infiltrate around dermal capillaries and keratotic plugging of follicles. A renal biopsy was also performed. This contained 16 glomeruli; they all showed early mesangial amyloid deposits which stained typically with cresyl violet and Sirius red. 
The latter stain was sensitive to pretreatment with potassium permanganate, resulting in loss of staining, typical of amyloid-A fibrils. ${ }^{4}$ Amyloid was quantitated at $12 \%$ of glomerular volume. There were no features to suggest any form of lupus nephritis. A rectal biopsy also showed amyloid.

The patient's renal function deteriorated rapidly, and in November 1981 he was excreting $8.5 \mathrm{~g}$ protein/24 hours with a creatinine clearance of 25 $\mathrm{ml} / \mathrm{min}$. He then developed ischaemia of his left lower limb, eventually requiring a mid-thigh amputation.

He died in December 1981. At necropsy the cause of death was found to be septicaemia and disseminated intravascular coagulation, with uraemia due to severe renal amyloidosis. Quantitation on the post-mortem kidney showed that amyloid was now $31.6 \%$ of the glomerular volume, an increase of $155 \%$ in the six months since the previous renal biopsy. Systemic amyloidosis was confirmed, with no evidence of vasculitis.

\section{Discussion}

The association between SLE and secondary amyloidosis is most unusual. In previous reports the association might be explained by the presence of an added condition known to cause amyloidosis. In our patient, however, as in that of Huston et al, ${ }^{5}$ there was no other such disorder. He did suffer chronic leg ulceration, but there was no evidence on admission of infection or underlying osteomyelitis. It is unlikely that the ulcer was the cause of amyloidosis developing in this patient, for, if this condition had amyloidogenic potential, amyloidosis would be far more common.

This patient demonstrated a clinical picture typical of subacute cutaneous lupus erythematosus (SCLE). ${ }^{2}$ The predominance of cutaneous manifestations, the mild systemic features, and the chronic indolent course shown by our patient are typical of this subset of SLE. Antibody to the cytoplasmic glycoprotein, $\operatorname{Ro}(\mathrm{SSA})$, is commonly found in SCLE, and the ANA test may remain persistently negative ${ }^{3}$ as it did in this case.

As in previous reports, our patient had SLE for several years before amyloidosis was detected, and the chronicity of the disease may be relevant as with other causes of secondary amyloidosis.

Active SLE is characterised by an abnormal acute phase response in which elevation of CRP is absent. ${ }^{6}$ More recently, de Beer et al. ${ }^{1}$ have investigated SAA in various chronic inflammatory conditions. High levels of SAA correlated with severity of disease and development of amyloidosis and rheumatoid arthritis. In contrast, patients with SLE did not develop amyloidosis and had only modest elevations of SAA even in the presence of severe disease.

The finding in our patient of a greatly elevated level of SAA in the absence of infection with the apparently very rare association of SLE and amyloidosis provides further evidence that persistent elevation of SAA is associated with the subsequent development of reactive amyloidosis.

We thank Dr John Whicher, consultant chemical pathologist, Bristol Royal Infirmary, for the analysis of acute phase reactants, and Mrs $\mathbf{J}$. Poulding for the quantitation of the renal amyloid.

\section{References}

1 De Beer F C, Mallya R K, Fagan E, Lanham J G, Hughes G R V, Pepys M B. Serum amyloid-A protein concentration in inflammatory diseases and its relationship to the incidence of reactive systemic amyloidosis. Lancet 1982; ii: 231-3.

2 Sontheimer R D, Thomas J R, Gilliam J N. Subacute cutaneous lupus erythematosus. A cutaneous marker for a distinct lupus erythematosus subset. Arch Dermatol 1979; 115: 1409-15.

3 Maddison P J, Provost T T, Reichlin M. Serological findings in patients with 'ANA-negative' SLE. Medicine (Baltimore) 1981; 60: $87-94$.

4 Wright J R, Calkins E, Humphrey R L. Potassium permanganate reaction in amyloidosis: a histologic method to assist in differentiating forms of this disease. Lab Invest 1977; 36: 274-81.

5 Huston D, McAdam K P W, Balow J E, Bass R. Amyloidosis in systemic lupus erythematosus. Am J Med 1981; 70: 320-3.

6 Becker G J, Waldburger M, Hughes G R V, Pepys M B. Values of serum C-reactive protein measurement in the investigation of fever in systemic lupus erythematosus. Ann Rheum Dis 1980; 39: $50-2$. 